\title{
足関節外側副勒帯損傷のストレス撮影
}

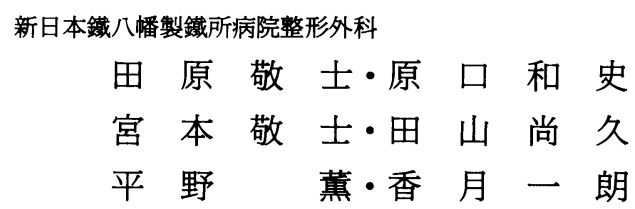

\section{Evaluation with Stresed X-P for the Dagnosis Treatment of Lateral Collaterla Ligament Injury of the Ankle}

by

\author{
Keiji Tahara, Kazusi Haraguchi, Keisi Miyamoto, \\ Naohisa Tayama, Kaoru Hirano and Ichirou Katsuki \\ Department of Orthopedic Surgery, \\ Nippon-Steel Corporation, Yahata Works Hospital, Kitakyushu Japan
}

67 cases with lateral collateral ligament injury of the ankle were operated on in our hospital during the 7 year period, 1986-1993. We evaluated Stressed X-P using measurements the degree of ligament tear (ATF only or ATF-CF complex tear) and compaired this with the findings at operation, with respect to onset of injury (acute or chronic) and the methods (Terose SE or manual).

There were no significant differences between the measurements on stressed X-P by using Terose SE or manual methods, and acute or chronic injury. Significant difference was shown regarding the Talar-Tilt angle on stressed X-P at the first visit between the above two groups by student $\mathrm{T}$-test.

There was no difference in the anterior drawer test. But Talar-Tilt angle measurements overlap each other between the single or complex tear group. That is, the Talar-Tilt angle measurements on stressed X-P is important for operative indications for treating this ligament injury, but is insufficient for judging single or complex tears.

Key words : collateral ligament lnjury of Ankle (足関節外側側副勒帯損傷), Stressed X-P (ストレス 撮影), Talar-Tilt angle (Talar Tilt), Anterior Drawer test (前方引き出し), Operative indication of lateral collateral ligament lnjury of Ankle（足関節外側側副靶 帯損傷の手術適応)

足関節外側側副靱帯損傷の治療法には大きく分けて 観血的治療と保存的治療がありまた保存的治療の中て もテーピングを含めた装具療法, ギプス, 早期運動療 法等色々な方法がある。我々は年秢の若い人，活動性 の高い人，スポーツ選手等には不安定性の改善が確実 な観血的治療を積極的に勧めてきた，足関節外側側副 勒帯損傷では, 通常無麻酔下にストレス撮影が行なわ
れそれを参考にして治療法が決定されることが多い。 しかしこれは患者の疼痛, 筋力, 手技の差等の影響を 受け信頼性に欠ける疑問が残る。

今回我々は観血的治療を行った症例においてストレ ス撮影の結果と術中所見の比較検討を行った。 
対

象

症例は昭和 61 年 1 月より平成 5 年 9 月までの過去 7 年間に観血的治療を行った 61 例 61 足関節で男 41 例女 20 例．年齢は 9 歳より 54 歳平均 22.6 歳。右 32 例左 29 例. 受傷歴では 2 回目以上の陳旧例 18 例, 新 鮮例 43 例. 術中所見では前距腓勒带単独損傷例 (以下 ATFのみ) 21 例，前距腓勒帯 + 踵腓靯帯複合損傷例 （以下 $\mathrm{ATF}+\mathrm{CF} ） 34$ 例，踵腓勒帯のみ損傷例 2 例， その他 4 例であった。踵腓靱帯のみ損傷例とその他の 例はそれぞれ症例数が少ない為 $\mathrm{ATF}+\mathrm{CF}$ と $\mathrm{ATF}$ の みについて検討を加えた。

（図 1 ）受傷原因としてはスポーツによるものが

受傷原因

\begin{tabular}{|c|c|c|}
\hline 種類 & 症例数 & $\%$ \\
\hline バスケット & 16 & 24 \\
\hline バレーボール & 13 & 20 \\
\hline サッカー & 7 & 11 \\
\hline インヂアカ & 3 & 5 \\
\hline ラグビー & 3 & 5 \\
\hline 野球 & 2 & 3 \\
\hline テニス & 1 & 2 \\
\hline ハードル & 1 & 2 \\
\hline ランニング & 1 & 2 \\
\hline スポーツ小計 & 47 & 71 \\
\hline 階段転落 & 7 & 11 \\
\hline 歩行中 & 5 & 8 \\
\hline 飛び降り & 3 & 5 \\
\hline 跳び箱 & 1 & 2 \\
\hline 自転車 & 1 & 2 \\
\hline その他 & 2 & 3 \\
\hline その他小計 & 19 & 29 \\
\hline 総計 & 66 & 100 \\
\hline \multicolumn{2}{|l}{} \\
\hline
\end{tabular}

図 1
71\%と多く中でもバスケットボール，バレーボールて 全体の 44\%を占めた。その他の原因としては階段転 落や歩行中の内反強制によるもの等が多い.

方法

ストレス撮影は無麻酔下に両側の内反強制と前方引 き出しを行なっている.

平成 4 年 3 月よりはテロス社製テロス $\mathrm{SE}$ を使用し ている。

ストレスX-Pより両側の内反ストレスでの距骨傾 斜角 Talar Tilt（以下 T-T) 前方引き出しでの頝骨 の後端と距骨の接線への距離（以下 $\mathrm{AD}$ ）を計測しそ れぞれ健側との差（以下 $\mathrm{T}-\mathrm{T}$ 差， $\mathrm{AD}$ 差）も計測し た（図 2 ).

症例を

1）ストレスのかけ方（徒手とテロス）

2 ）受傷時期による差（新鮮例と陳旧例）

3 ) 受傷勒帯の差 $(\mathrm{ATF}+\mathrm{CF}$ と ATF のみ)

に分けそれぞれを検討した。

\section{ストレス計測法}

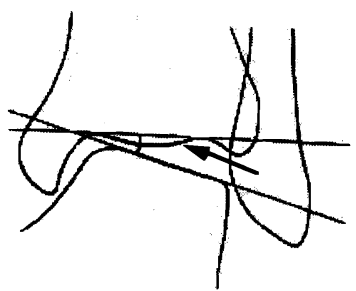

Talar Tilt

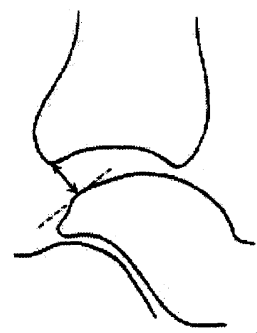

前方引き出し
図 2

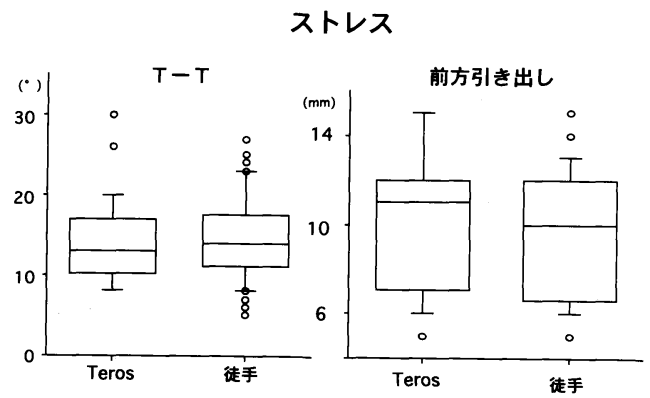

図 3 
有意差は T検定を用いて行なった。

結果

ストレス法の差では Telos SE と徒手の間では T $\mathrm{T}, \mathrm{T}-\mathrm{T}$ 差, $\mathrm{AD}, \mathrm{AD}$ 差とも有意な差は出なかった。

\section{受侮時期}

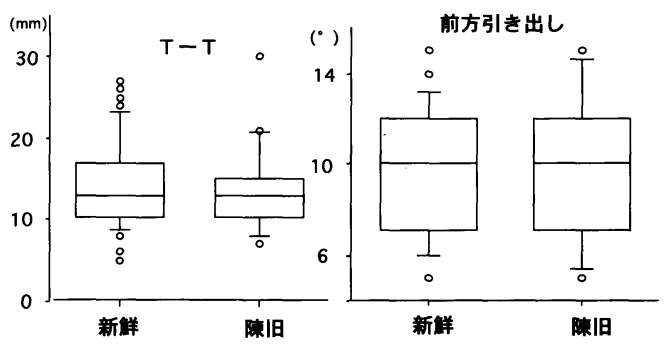

又新鮮例と陳旧例でもそれぞれ有意な差は出なかった (表 1，2）（図 3，4）. ATF +CF と ATF のみで は $\mathrm{T}-\mathrm{T}, \mathrm{AD}$ ともにそれぞれ健側とは有意な差があっ た (図 5 )。 T-Tでは ATF +CF 群は ATF のみ群よ り平均で約 $3^{\circ}$ 大きく有意な差が出た。

また $\mathrm{T}$ - $\mathrm{T}$ 差でも平均で約 $3{ }^{\circ}$ 大きく有意な差が出 た (図 6).

しかし $\mathrm{AD}, \mathrm{AD}$ 差にては健側に比べて有意な差は あるが, $\mathrm{ATF}$ のみ群と $\mathrm{ATF}+\mathrm{CF}$ 群両者に有意な差 は出なかった（図 7 ）（表 3 ）。その中で T-Tで $\mathrm{ATF}$ のみ群と $\mathrm{ATF}+\mathrm{CF}$ 群の重なるどちらとも言え ない領域（以下 Gray Zone）が $12^{\circ} \sim 16^{\circ}$ の範囲であ る。これは（図 8 ）で示すようにそれぞれのパーセン トタイル $95 \%$ で重なる部分とした。この中に ATF

図 4

表 1 ストレス法

\begin{tabular}{c|c|c|c|c}
\hline \hline & 患T-T & $\mathrm{T}$ - T 差 & 前方引き出し & 前方差 \\
\hline テロス (25 例) & $14.04 \pm 5.6$ & $8.16 \pm 5.01$ & $10.28 \pm 3.2$ & $3.04 \pm 1.86$ \\
\hline 徒手 (36 例) & $14.5 \pm 5.4$ & $8.22 \pm 5.24$ & $9.14 \pm 2.91$ & $3.75 \pm 2.43$ \\
\hline T検定 & 0.8473 & 0.8961 & 0.2812 & 0.3422 \\
\hline 有意差 & なし & なし & なし & なし \\
\hline
\end{tabular}

表 2 受傷時期

\begin{tabular}{c|c|c|c|c}
\hline & 患 T-T & T-T 差 & 前方引き出し & 前方差 \\
\hline 新鮮 (43 例) & $14.53 \pm 5.39$ & $8.16 \pm 5.4$ & $9.51 \pm 3.00$ & $3.37 \pm 2.31$ \\
\hline 陳旧 (18 例) & $13.79 \pm 5.51$ & $7.84 \pm 4.74$ & $9.95 \pm 3.21$ & $3.47 \pm 2.17$ \\
\hline T検定 & 0.5302 & 0.7795 & 0.5399 & 1 \\
\hline 有意差 & なし & なし & なし & なし \\
\hline
\end{tabular}

表 3 受傷靯帯

\begin{tabular}{c|c|c|c|c}
\hline & $\mathrm{T}-\mathrm{T}$ & $\mathrm{T}$-T 差 & 前方引き出し & 前方差 \\
\hline $\mathrm{ATF}+\mathrm{CF}(34$ 例 $)$ & $15.74 \pm 5.23$ & $9.53 \pm 5.19$ & $9.68 \pm 3.03$ & $3.53 \pm 2.03$ \\
\hline $\mathrm{ATF}$ の $(21$ 例 $)$ & $12.76 \pm 5.39$ & $6.95 \pm 4.73$ & $10.1 \pm 3.13$ & $3.81 \pm 2.56$ \\
\hline $\mathrm{T}$ 検定 & 0.0424 & 0.0437 & 0.153 & 0.6608 \\
\hline 有意差 & 有 & 有 & なし & なし \\
\hline
\end{tabular}

表 4 T-T

\begin{tabular}{c|c|c|c|c|c|c}
\hline \hline & 症例数 & 平均 $\left(^{\circ}\right)$ & 標準偏差 & 最小 & 最大 & Gray Zone \\
\hline $\mathrm{ATF}+\mathrm{CF}$ & 34 & 15.74 & 5.23 & 8 & 27 & $14 / 34(41.2 \%)$ \\
$\mathrm{ATF}$ のみ & 21 & 12.76 & 5.39 & 5 & 30 & $8 / 21(38.1 \%)$ \\
\hline 全体 & 61 & 14.31 & 5.44 & 5 & 30 & $24 / 61(39.3 \%)$ \\
\hline
\end{tabular}

表 5 T-T 差

\begin{tabular}{c|c|c|c|c|c|c}
\hline \hline & 症例数 & 平均 $\left(^{\circ}\right)$ & 標準偏差 & 最小 & 最大 & Gray Zone \\
\hline $\mathrm{ATF}+\mathrm{CF}$ & 34 & 9.53 & 5.19 & 0 & 19 & $11 / 34(32.3 \%)$ \\
$\mathrm{ATF}$ のみ & 21 & 6.95 & 4.73 & 0 & 20 & $8 / 21(38.1 \%)$ \\
\hline 全体 & 61 & 8.2 & 5.1 & 0 & 20 & $19 / 61(31.1 \%)$ \\
\hline
\end{tabular}



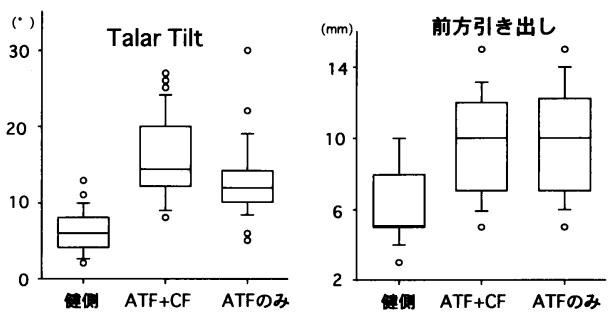

図 5
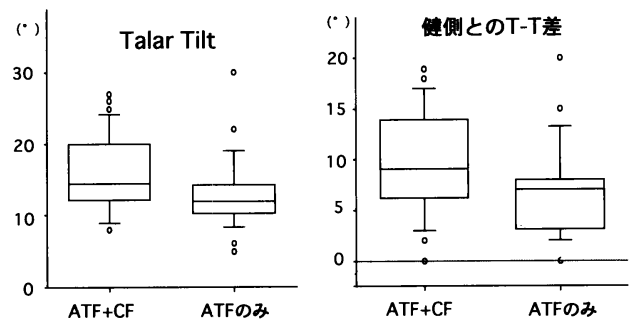

図 6
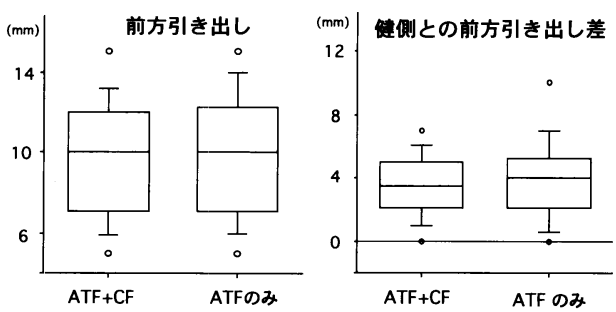

図7
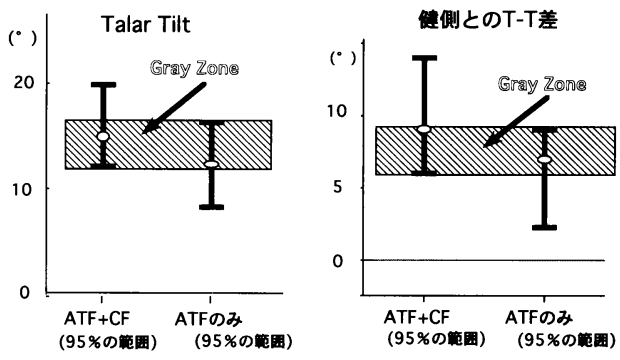

図 8

のみ群 21 例中 8 例 $(38.1 \%), \mathrm{ATF}+\mathrm{CF}$ 群 34 例中 14 例 (41.2\%) が入る（表 4 ).

また T-T差でも同様に（ $6^{\circ} \sim 9^{\circ} ）$ の範囲で Gray Zone に ATF のみ群 21 例中 8 例 (38.1\%), $\mathrm{ATF}+\mathrm{CF}$ 群 34 例中 11 例 (32.3\%）が入る（表 5 ).

\begin{tabular}{c|c}
\multicolumn{2}{c}{ 表 6 } \\
\hline \multicolumn{2}{c}{ ATF 損傷あり } \\
\hline $\begin{array}{c}\text { Lee }(1957)^{11)} \\
\text { Cox }(1979)^{5)}\end{array}$ & $5^{\circ}$ 以上 \\
\hline $\begin{array}{c}\text { Freeman }(1965)^{6)} \\
\text { Glasgou }(1980)^{7)}\end{array}$ & $6^{\circ}$ 以上 \\
\hline $\begin{array}{c}\text { Anderson }(1954)^{1)} \\
\text { 川上 }(1986)^{1)}\end{array}$ & $7^{\circ}$ 以上 \\
\hline Sedlin $(1960)^{14}$ & $15^{\circ}$ 以上 \\
\hline Gould $(1980)^{8)}$ & $18^{\circ}$ 以上 \\
\hline Rubin $(1960)^{13)}$ & $23^{\circ}$ 以上
\end{tabular}

\begin{tabular}{c|c|c}
\multicolumn{3}{c}{ 表 7 } \\
\hline & ATF 単独損傷 & ATF + CF 複合損傷 \\
\hline Black $(1977)^{2)}$ & $10^{\circ}$ 以下 & $20^{\circ}$ 以上 \\
\hline Bonnin $(1944)^{3)}$ & $14^{\circ}$ 以下 & $15^{\circ} \sim 30^{\circ}$ \\
\hline Hughes $(1949)^{9)}$ & $8^{\circ} \sim 20^{\circ}$ & $18^{\circ} \sim 20^{\circ}$ \\
\hline 中島 $(1984)^{\text {D) }}$ & & $15^{\circ}$ 以上 \\
\hline Brostrom $(1964)^{4)}$ & $5^{\circ} \sim 16^{\circ}$ & $5^{\circ} \sim 23^{\circ}$ \\
\hline Watson-Jonens $(1975)^{15)}$ & $5^{\circ} \sim 15^{\circ}$ & $15^{\circ} \sim 30^{\circ}$ \\
\hline
\end{tabular}

（治療方針）

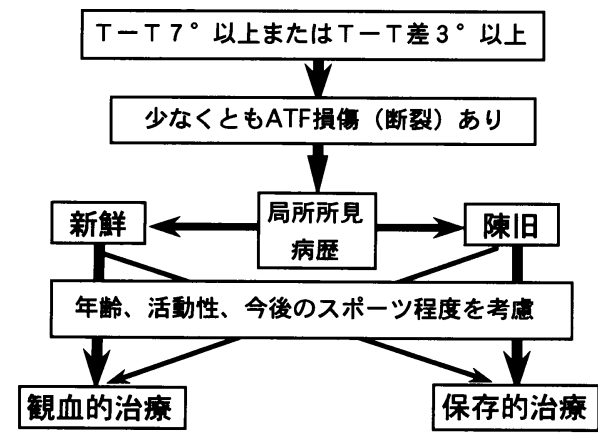

図 9

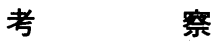

TーT を定量的に分析した諸家の報告をまとめると (表 6 ) ATF 損傷ありとする範囲は $5^{\circ} \sim 23^{\circ}$ と様々 で単独損傷と複合損傷でも範囲のばらつきは多いよう である(表 7 )。

今回我々の結果では $\mathrm{T}-\mathrm{T} 7^{\circ}$ 以上, $\mathrm{T}-\mathrm{T}$ 差 $3^{\circ}$ 以上, $\mathrm{AD} 7 \mathrm{~mm}$ 以上, $\mathrm{AD}$ 差 $2 \mathrm{~mm}$ 以上で少なくとも $\mathrm{ATF}$ 損傷 (断裂) がある可能性が強い.

観血的治療の適応についても様々であるが複合靶帯 損傷では観血的治療を勧めるものが多い.しかし我々 
の印象では Gray Zone に入る症例も多く T-T や T $\mathrm{T}$ 差の数值のみで単独損傷か複合損傷かの診断をつ けるのは難しく, それのみで観血的治療の適応を決定 するには問題が多いと考えている。

我々の治療方針としては今回受傷例で T-T $7^{\circ}$ 以上, $\mathrm{T}-\mathrm{T}$ 差 $3^{\circ}$ 以上 $\mathrm{AD} 7 \mathrm{~mm}$ 以上, $\mathrm{AD}$ 差 $2 \mathrm{~mm}$ 以上の 例には少なくともATF 損傷（断裂）あると考えてい る (図 9 ). さらに受傷歴, 局所の腫脹の程度より新 鮮損傷と思われる例では年齢の若い人，活動性の高い 人，スポーツ選手等には不安定性の改善が最も確実な 観血的治療を勧める。

局所所見から陳旧性と思われる例では，繰り返す捻 挫等の病歴がない場合は保存的治療にて経過を見るこ とを原則としている。

\section{要 約}

1 ) 過去 7 年間に足関節外側側副勒帯損傷で観血的治 療を行なった 67 例のストレスX線評価を行なった。

2 ）新鮮例と陳旧例，徒手とテロスによるストレスで は，T-T， $\mathrm{AD}$ 共に有意な差はなかった。

3 ) ATF 単独損傷例と $\mathrm{ATF}+\mathrm{CF}$ 複合損傷例では $\mathrm{T}-\mathrm{T} ， \mathrm{~T}-\mathrm{T}$ 差にて有意な差が見られるが， $\mathrm{AD}$ や $\mathrm{AD}$ 差では有意な差は見られなかった。

4 ) $\mathrm{TF}$ 単独損傷例と $\mathrm{ATF}+\mathrm{CF}$ 複合損傷例の $\mathrm{T}-\mathrm{T}$, $\mathrm{T}-\mathrm{T}$ 差で Gray Zone に入る症例も多くストレスX 線評価のみにて確定診断や手術適応を決めるのは難 しく思えた。

\section{参考 文 献}

1) Anderson, K. J. and Le Cocq, J. F. : Operative treatment of injury to the fibular colateral ligament of the ankle. J. Bone Joint Surg., 36-A : 825-832, 1954.

2) Black, H. : Operative treatment-acute and chronic. Am. J. Sports Med., 5 : 256-257, 1977.

3) Bonnin, J. G. : The hypermobile ankle. Proc. Roy. Soc. Med., 37 : 282-286, 1944

4) Brostrom, L. : Sprained ankles, I. Anatomic lesions in recent sprains. Acta Chir. Scand., 128 : $483-495$, 1964.

5) Cox, J. S. and Hews, T. F. : Normal talar tilt angle. Clin. Orthop., $140: 37-41,1979$.

6) Freeman, M, A. R. : Treatment of ruptures of the lateral ligament of the ankle. J. Bone Joint Surg., 47B : 661-668, 1965.

7) Glasgow, M., et al. : Instability of the ankle injury to the lateral ligament. J. Bone Joint Surg., 62 - B : 196-200, 1980

8) Gould, N., et al. : Eary and late repair of lateral ligament of the ankle. Foot Ankle, 1:84-89, 1980.

9) Hughes, J. R. : Rodiological daiagnosis of recent lesions of the lateral ligament of the ankle. J. Bone Joint Surg., 31-A : 478, 1949.

10）川上登：足部靯帯損傷の診断法。整形外科 $\mathrm{MOOK}$, $43: 37-50,1986$.

11) Lee, H. G. : Surgical repair in recurrent dislocation of the ankle joint. J. Bone Joint Surg., 39-A : 828-834, 1957.

12）中島寛之：足関節靶帯損傷について，日整会誌，58： 1303-1314, 1984.

13) Rubin, G. and Witten, M. : The talar tilt angle and the fibular colaterla ligaments J. Bone Joint Surg., 42A : $311-326,1960$

14) Sedin, C. E. D. : A device for stress inversion or eversion roentogenograms of the ankle. J. Bone Joint Surg., 42-A : 1184-1190, 1960.

15) Watson-Jonens, R. : Fractures and Joint Injuries. 4th ed. Williams \& Wilkins. Baltimore, $817-823$, 1955. 